\title{
AQUISIÇÃO DO LÉXICO NA APRENDIZAGEM DO PORTUGUÊS L2: O CASO DE ANGOLA
}

Maria João Marçalo (U. Évora) João Muteteca Nauege (U. Évora)

Resumo: A reflexão sobre aquisição do léxico na aprendizagem do PL2 no contexto angolano aborda a necessidade de se repensar o ensinoaprendizagem do léxico por meio da sua faceta activa o vocabulário, podendo ser feito de uma forma explícita para que as aprendizagens sejam mais sólidas. Fazendo um nexo com a realidade angolana, acresce outra discussão que tem que ver com metodologias explícitas para se ensinar o léxico e o vocabulário, com base em metodologia de PL2.

Palavras-chave: Aquisição; Léxico; Português L2.

Abstract: The reflection on the acquisition of the lexicon in the learning of PL2 in the Angolan context addresses the need to rethink the teaching-learning of the lexicon through its active facet vocabulary, and can be done in an explicit way so that learning is more solid. Making a connection with the Angolan reality, there is another discussion that has to do with explicit methodologies to teach the lexicon and vocabulary, based on PL2 methodology.

Keywords: Acquisition; Lexicon; Portuguese L2

\section{INTRODUÇÃO}

A aquisição do léxico na aprendizagem de uma língua segunda não é uma tarefa muito fácil, a julgar pelo facto de o português em Angola ser a língua segunda para a maioria de seus falantes, bem como a ser ensinado com metodologias de língua primeira. Dizemos, praticamente, língua primeira, porque não há, até ao momento, nenhuma diretiva oficial do Instituto Nacional de Investigação e Desenvolvimento 
de Educação (INIDE), que oriente ou explicite a metodologia a ser adoptada em relação ao ensino do português como língua segunda ou como língua materna. Mas o INIDE no Programa de Língua Portuguesa, 6a classe (s/d:2) reconhece também que:

\begin{abstract}
A Língua Portuguesa não é, para a maioria das crianças angolanas, a sua língua materna; daí o cuidado de, no Ensino Primário, se adoptarem métodos e técnicas eficazes, capazes de levar os alunos a efectuar pacífica e conscientemente a transição das aprendizagens da convivência do círculo familiar e social para a aprendizagem e conhecimento de conteúdos devidamente estruturados e ministrados nas instituições de ensino.
\end{abstract}

Lembre-se de que a constituição da República de Angola assegura no seu artigo 19 sobre línguas que "a língua oficial da República de Angola é o português". Parece-nos urgir já a necessidade de se clarificar a metodologia consentânea para o ensino do português em Angola, quer como língua segunda, quer como língua materna, tendo em conta o contexto e a realidade dos aprendentes, como temos defendido.

\title{
1. LÉXICO VS. VOCABULÁRIO
}

É comum encontrarem-se várias definições a respeito do léxico, a multiplicidade de definições indica, como é óbvio, o carácter complexo de que se reveste o estudo do léxico 
de uma língua. Fazendo recurso ao Dicionário de termos linguísticos de Xavier \& Mateus (1992) pode encontrar-se a seguinte definição:

Entende-se por léxico o conjunto de formas atestadas correspondendo a uma zona lexical comum a todos os locutores de uma comunidade (...) sendo também conjunto de unidades lexicais comuns à significação, isto é, a parte do semema que é do domínio comum da comunidade. (p.225)

Como se pode depreender, o léxico não tem carácter finito e imutável, talvez, estas peculiaridades contribuam para a sua complexidade no que concerne à sua delimitação e abordagem linguística, uma vez que, dia após dia surgem novas palavras através dos vários processos de que a língua dispõe para a sua renovação e o seu enriquecimento.

Na senda das definições do léxico, Hatch \& Brown (1995, p.1) referem que: “(...) the term lexicon refers to the overall system of words forms and, when we include morphology, the study of word formation in language. The term is also used to refer to the way forms might be systematically represented in brain, that is, the mental lexicon".

Basílio destaca que o léxico não pode ser considerado como "uma mera lista de entradas lexicais, caso em que a competência lexical corresponderia ao conhecimento desta lista; nem pode ser considerado apenas como um conjunto de regras (...)" (1980, p.8-9). 
A ideia defendida por Hatch \& Brown (1995) e Basílio (1980) traz a lume a "velha" visão que se tem de léxico e, em parte, procura esclarecer que o léxico não é apenas uma simples lista de palavras dicionarizadas, porque se assim fosse a competência lexical de um falante não envolveria a obediência às regras, a sua capacidade de relacionar os itens lexicais, a contextualização do discurso e a formação de palavras novas.

Sublinhe-se que nas diferentes definições podem encontrar-se pontos de contacto quando se trata de léxico, tais como:

i) conjunto das unidades que formam a língua de uma comunidade;

ii) repositório de todo um saber linguístico partilhado por uma comunidade falante de uma língua;

iii) é heterogéneo, deveras dinâmico, e está ao serviço da actividade humana.

\section{VOCABULÁRIO}

Toda a competência lexical de que dispõe um indivíduo, manifesta-se no seu vocabulário e muitas vezes há dificuldades em delimitar as fronteiras entre vocabulário e léxico. $\mathrm{O}$ conhecimento do vocabulário torna-se indispensável em qualquer língua. De acordo com Hatch \& Brown (1995, p.1), 
"the term vocabulary refers to a list or set of words for a particular language or a list of words that individual speakers of language might use".

Vilela (1995, p.13) distingue do seguinte modo o léxico do vocabulário: "O léxico é o conjunto das palavras fundamentais, das palavras ideais de uma língua; o vocabulário é o conjunto dos vocábulos realmente existentes num determinado lugar e num determinado tempo, tempo e lugar ocupados por uma comunidade linguística". E acrescenta, ainda, que: "O léxico é o geral, o social e o essencial; o vocabulário é o particular, o individual e o acessório" (1995, p.13).

Deduz-se, nestes termos, que o vocabulário é a parte activa do léxico de uma língua, sendo o léxico (todo o espólio) a parte passiva dessa mesma língua, por outras palavras, o léxico é o conjunto de palavras de que uma língua dispõe, ao qual o falante recorre e faz a seleção de palavras de que precisa para uso imediato no quotidiano.

\section{AQUISIÇÃO DO LÉXICO}

Reconhece-se que a aquisição de léxico é o esteio de aprendizagem de uma língua quer seja primeira, quer seja segunda. Durante anos, estudos para a compreensão de mecanismos que envolvem a aquisição de léxico foram ignorados ou simplesmente relegados para planos 
secundários, tendo-se dado ênfase a áreas como fonética e fonologia, morfologia, sintaxe e semântica, só para citar algumas, como resultado a aquisição de léxico foi sempre de forma implícita ou incidental, ou seja, mesmo que se reconheça que a aquisição de léxico se faz de modo incidental, sabe-se, se fosse de modo sistematizado os resultados seriam melhores.

De acordo com Nagy (1988, Apud Giasson, 1993, p.255), as crianças dos 9 (nove) aos 12 (doze) anos de idade podem adquirir cerca de 3000 palavras, embora o número de palavras possa variar grandemente de aluno para aluno.

Sabendo-se que a aquisição de léxico, maioritariamente, se faz incidentalmente, quer dizer, sob diferentes vias se adquire uma determinada quantidade de vocabulário, podendo ser nas suas interações sociais com colegas, pais e leituras pessoais, o contributo da escola ainda não é o desejado, por não ser ainda explícito.

Giasson (1993, p.225) assevera "que o contributo das leituras pessoais é, precisamente, o factor mais susceptível de explicar a rapidez da aquisição do vocabulário e a disparidade desta aquisição nos alunos".

A aquisição de léxico varia de indivíduo para indivíduo, ou seja, dois alunos que partilham a mesma sala de aulas poderão 
mostrar níveis de desenvolvimento lexical diferenciados, devido à condição socio-económica que cada um deles ostenta. Investigações que comprovam esse ponto de vista são de Snow, Barnes, Chandler, Goodman \& Hemphill (1992, Apud Duarte, 2011, p.9), as quais mostram que: (...) os filhos de profissionais diferenciados são expostos a mais de $50 \%$ de palavras do que os filhos de trabalhadores manuais (...)

Quer dizer que quanto mais as crianças estiverem expostas aos materiais e ambientes sociais propiciadores de desenvolvimento do capital lexical, maior é a possibilidade de o adquirir e desenvolvê-lo, mesmo que seja de forma não consciente.

O ensino e a aprendizagem do vocabulário podem ser feitos por via indireta, a também chamada incidental ou não sistemática ou por via direta ou sistemática. A via indireta privilegia a aquisição do vocabulário com base no contexto, tendo-o como suficiente para aquisição ou aprendizagem vocabular, utilizando leituras pessoais de forma não sistemática e não rígida.

A via direta ou sistemática dá ênfase ao ensino e aprendizagem sistematizados do vocabulário, portanto, objeta que a aquisição ou aprendizagem do vocabulário com base no contexto e leituras pessoais sejam suficientes 
e eficazes, por que: “o contexto nem sempre é suficiente para que o leitor descubra o sentido de uma palavra nova numa única ocorrência" (Giasson, 1993, p.261).

Os defensores da via sistemática ou direta asseveram que se o papel das leituras pessoais dos alunos na aquisição do vocabulário é fundamental, então não se deveria deixar de lado o ensino explícito do vocabulário que se deve processar na aula. Assim, as intervenções pedagógicas consistiriam em:

(i) criar ou acrescentar a motivação do aluno para se envolver (ainda mais) ${ }^{1}$ em leituras pessoais na aula e fora dela;

(ii) o ensino das estratégias que permitem aos alunos partir do contexto para descobrir o sentido de palavras desconhecidas;

(iii) o ensino direto sobre as palavras de vocabulário específicas (Giasson, 1993, p.256).

Quer uma abordagem quer outra pode funcionar perfeitamente e surtir efeitos que se desejam para o ensino eficaz e eficiente do léxico (vocabulário) aos alunos, não havendo uma melhor do que outra, havendo apenas necessidade de se adaptar à realidade dos aprendizes, dito de outro modo, tudo depende do tipo de vocabulário que

1 Grifo nosso 
se vai adquirir, o escopo do aprendente, a faixa etária e o contexto em que ocorre a instrução.

Várias razões atinentes às características do próprio léxico são aventadas como as que têm estado na base de dificuldades de não didactização explícita do léxico, por exemplo,

das características do léxico, as mais invocadas são sobretudo a sua extensão e o seu carácter aberto (...), não heterogénea, irregular, mas até caótica (...) objecto não passível de descrição sistemática, objecto incompleto ou insuficientemente descrito que aparece, não apenas ao olhar intuitivo do falante, mas também, ao que transparece das palavras do autor, do lexicólogo, como um todo extremamente "cáotico" dificilmente se entenderá como objecto didactizável. (PINTO, 2012, p.75)

Este ponto de vista reflete de modo peremptório, as dificuldades encontradas para o estabelecimento ou, se não mesmo, para a definição de parâmetros didáticos claros para o ensino do léxico nos programas de língua portuguesa.

Há toda a necessidade de se definir parâmetros didáticos para o ensino do léxico, por que a aquisição e o desenvolvimento de competência lexical estão entre os objetivos primordiais, específicos e gerais; primeiro do ensino primário e depois da disciplina da língua portuguesa como 
disciplina curricular em Angola (cf. Lei de Bases do Sistema de Educação-Angola, 2001; Programa Melhorado do Ensino Primário 6ạ classe- Língua Portuguesa, INIDE s/d).

\section{IMPLICAÇÕES DA AQUISIÇÃO DO LÉXICO NA ORALIDADE, NA LEITURA E NA ESCRITA}

É razoável que a escola angolana, de entre várias atribuições que Ihe são acometidas, encare e privilegie práticas que estimulem o uso da língua portuguesa, eficaz e eficientemente por parte dos seus alunos como uma possibilidade de atingir aprendizagens significativas em todo o processo de formação, dado que todo o ensinoaprendizagem se desenvolve em português.

\subsection{Na oralidade}

A escola joga um papel importante no desenvolvimento da competência lexical dos alunos, mas há uma indefinição ou falta de posicionamento claro, das escolas em relação ao ensino da oralidade, privilegiando-se a leitura e a escrita, ficando de parte a oralidade. Esquece-se a própria escola que de entre várias funções que lhe são atribuídas pela sociedade no ensino e aprendizagem de uma língua, está como refere Sim-Sim: "a de desenvolver no aluno as capacidades de argumentação e de expressão em contextos diversificados, visando audiências diferentes e intenções variadas, deverá constituir uma meta no ensino (...)" (1998, p.32). 
Atendendo às dificuldades com que se depara, no quotidiano, o professor de língua portuguesa em Angola para ensinar o português em contexto em que apesar de os alunos terem outras línguas maternas aprendem o português, também, como língua materna, e por não haver metodologias específicas para ensinar o português de acordo com a realidade de cada aluno, urge necessidade de se definir estratégias metodológicas para o ensino da oralidade nas escolas angolanas. Modéstia à parte, não é, nem será tarefa fácil, pois exigirá de todos os atores (professores) a concentração de esforços para uma única direção.

Mensurar a capacidade oral de cada aluno é a tarefa mais fácil que o indivíduo pertencente a uma comunidade linguística tem, difícil é ajudar a construir esta capacidade oral que o aluno deveria possuir, até certo nível ou padrão escolar, porque como enfatiza Sim-Sim:

Saber expressar-se significa ser eficaz na comunicação oral, i.e., ser capaz de transmitir com exactidão qualquer informação, em contextos diversificados (...). $\mathrm{O}$ desenvolvimento da oralidade reflecte-se no uso claro, estratégico, crítico e criativo da língua e implica o crescimento em termos de conteúdo linguístico, do reportório de estratégias de interacção e da flexibilização do uso em actividades e situações variadas (1998, p.35). 
Todas as estratégias metodológicas que forem adoptadas para o ensino-aprendizagem da oralidade, quer para os alunos que têm o português como língua materna quer para os alunos que o têm como língua segunda, poderão resultar se se tiver professores à altura dos desafios, porque o professor como gestor e facilitador das aprendizagens de alunos faz sempre a diferença na construção sólida das aprendizagens, ou seja, dever-se-ia, sempre, atualizar os conhecimentos dos professores com ferramentas novas de acordo com as exigências atuais, incutindo-Ihes a necessidade de verem o aluno como o centro das aprendizagens e verem-se a si mesmos como facilitadores ou coadjutores dessa tarefa.

\subsection{Na leitura}

A leitura constitui-se em peça-chave para todas as aprendizagens a desenvolver fora e dentro da escola, dada a sua importância e complexidade, ela deve ser bem ensinada para ser bem aprendida, envolve conjunto de técnicas que devem ser do domínio dos professores que se propõem a transmiti-la aos seus alunos.

Com a dinâmica das sociedades, Angola não é um caso à parte, sobretudo com o advento das novas tecnologias, a leitura parece estar a perder o lugar cimeiro que sempre teve na aquisição de múltiplos saberes por parte dos alunos, todavia as novas tecnologias de informação e comunicação 
(Tic), também, estão ao serviço da leitura, pois, veja-se que o acesso a diversas informações na internet se faz por intermédio da leitura, por isso, ela precisa de ser estimulada e incentivada sob diversas formas na escola e fora dela.

A prática de leitura, sob diversas formas, é sempre enriquecedora para aquisição e desenvolvimento da competência lexical do aluno, atente-se à afirmação de Duarte (2011)

para que a leitura potencie ao máximo o enriquecimento do capital lexical das crianças, convém que elas leiam tanto textos simples, que não lhes colocam problemas de compreensão, como textos, mais complexos, que constituam desafios quer do ponto de vista da complexidade estrutural quer do ponto de vista do vocabulário. (p.23)

O princípio de gradualismo "natura non facit saltus," deve ser observado na seleção e orientação do tipo de textos que os alunos devem apropriar-se nas atividades leitoras.

É consenso de quase todos os pesquisadores em matéria de literacia, aquisição e desenvolvimento da linguagem, que há uma proporcionalidade entre a leitura, aquisição e desenvolvimento do capital lexical do aluno, ideia partilhada por Giasson (1993, p.225): “(...) nos últimos anos, certas pesquisas revelaram que a aquisição do vocabulário se efetua por etapas através da leitura de numerosos textos". 


\subsection{Na escrita}

A escrita, à semelhança da oralidade e da leitura, constitui uma das tarefas fundamentais que a escola tem de resolver ao se dar o início da escolarização fundamental de qualquer indivíduo, porque também se constitui em um indicador de base na análise da eficácia do sistema educativo do País.

Reconhece-se, hoje, que grande parte de alunos no ensino primário, e não só, em Angola, apresenta dificuldades assinaláveis de escrita que se arrastam até à sua vida fora da escola. As dificuldades devem-se, sobretudo, à falta de estratégias didáticas específicas que devem ser materializadas por professores nas suas aulas e pelo facto de tais estratégias exigirem dos professores uma formação específica que muitas vezes não detêm. Tratando-se de uma questão tão complexa, o ensino da escrita não seria devotado apenas ao ensino primário como fazem crer as práticas educativas. A escrita não se consegue num ciclo de ensino só, é das habilidades mais complexas que o aluno deve treinar indefinidamente.

Carvalho (2011)concebe a escrita como

o oposto da oralidade, esta assenta num sistema fonológico e materializada em sons, aquela num sistema ortográfico e materializada em símbolos gráficos visíveis numa superfície. A correspondência entre as 
unidades constituintes do código oral e as do código escrito, entre o sistema fonológico e o sistema ortográfico, não é unívoca e linear. (p.79)

O carácter não unívoco entre o grafema e o fonema, sobretudo na escrita da língua (portuguesa) objeto em análise, constitui uma das razões para a complexidade da sua aprendizagem.

O ensino da oralidade, da leitura e da escrita não deve ser feito de forma isolada, pelo contrário, deve haver uma harmonização dos diversos instrumentos que concorrem para o mesmo, a aquisição e o desenvolvimento da competência lexical em português língua segunda conseguem-se e podem ser melhorados quando o ensino primário concretizar o trinómio: oralidade, leitura e escrita de forma eficiente e eficaz. A esse respeito, Lubliner \& Smetana (2005) afirmam:

o capital lexical é igualmente um factor determinante da qualidade da escrita. Com efeito, quanto maior for, tanto maiores são os recursos disponíveis para selecionar vocabulário preciso e para evitar repetições lexicais (...) este capital lexical influencia e é influenciado pelo volume de leituras e pelo nível atingido na compreensão da leitura, são factores que favorecem a qualidade da produção escrita, a qual, por sua vez, tem efeitos na compreensão da leitura (...) e "desencadeia a espiral ascendente que conduz ao sucesso escolar (DUARTE, 2011, p.9-10). 
O encadeamento harmonioso das habilidades de oralidade, leitura e escrita surge, também no quadro dos objetivos gerais do ensino da língua portuguesa, quer no quadro mais amplo, a Lei de bases do sistema de Educação em Angola (2001) que no seu artigo 17으 postula como um dos objetivos específicos do ensino primário, "desenvolver e aperfeiçoar o domínio da comunicação e da expressão", quer no mais estrito, no de objetivos gerais da disciplina da língua portuguesa no ensino primário, dentre os quais se destacam no programa melhorado do ensino primário 6ạ classe língua portuguesa os seguintes:

Conhecer a língua nas suas variantes oral e escrita;

Aplicar a língua na comunicação e expressão oral e escrita;

Conhecer os princípios e procedimentos linguísticos e comunicativos relativos à oralidade, à leitura e à escrita;

Analisar os aspetos ligados à língua portuguesa, utilizando-os como base de aquisição de conhecimentos dos conteúdos de outras disciplinas. (LEI DE BASES DO SISTEMA DE EDUCAÇÃO, 2001, p.8)

Estes objetivos elucidam quão é importante a apreensão com eficácia da oralidade, da leitura e da escrita, e estas habilidades devem ser convenientemente ensinadas para serem desenvolvidas. 


\section{CONSIDERAÇÕES FINAIS}

A aquisição do léxico, lato sensu, e da sua faceta ativa, vocabulário, para os alunos angolanos, que a sua larga maioria tem o português como língua segunda e de escolaridade, afigura-se como parte de objetivos fundamentais a serem atingidos no quadro da escolaridade fundamental ou primária.

O desenvolvimento encadeado das habilidades oral, leitora e escrita, só é possível com uma aquisição e desenvolvimento plenos da competência lexical que se pode aferir com base no domínio de diversas formas de expressão e comunicação por parte do aluno ao apropriar-se e fazer uso das habilidades que envolvem a expressão oral, a expressão escrita e a leitura.

Ressalte-se que a aquisição/aprendizagem do léxico, sobretudo a sua faceta activa, vocabulário, é vista principalmente sob dois prismas diferentes, que são a via direta e a via indireta ou incidental, no caso concreto da realidade angolana, a via direta que se consubstancia num ensino de léxico mais orientado e não incidental teria resultados mais satisfatórios, dado que uma franja considerável dos falantes de língua portuguesa a têm como L2. E o facto de a via incidental orientar a prática de leitura como o principal meio para 
aquisição e desenvolvimento lexical, prática esta que, ainda, precisa de ser mais estimulada, por os níveis de literacia se apresentarem consideravelmente baixos em Angola.

\section{REFERÊNCIAS}

BASÍLIO, Margarida (1980). Estruturas Lexicais do Português: Uma abordagem gerativa. Editora Vozes. Petrópolis.

CARVALHO, José António Brandão (2011). “A Escrita como Objecto EscolarContributo para a sua R(e) configuração". In: DUARTE, Isabel; FIGUEIREDO Olívia (Orgs). Português Língua e Ensino. Editora Universidade Porto. Porto. p.77-106.

DUARTE, Inês (2011). O conhecimento da Língua: Desenvolver a consciência Lexical. Colaboração de Madalena Colaço e outras. Ministério da Educação. Lisboa.

FIGUEIREDO, Olívia (2011). "Ensino Aprendizagem do Léxico. Orientações Metodológicas". In: DUARTE, Isabel; FIGUEIREDO, Olívia (Orgs). Português Língua e Ensino. Editora Universidade Porto. Porto. p.345-362.

GIASSON, Jocelyne (1993). A compreensão na Leitura. Edições ASA.

HATCH, Evelin.; BROWN., Cheryl (1995). Vocabulary, Semantics and Language Education. Cambridge. CUP.

Lei de Bases do Sistema de Educação (2001), Assembleia Nacional de Angola. In http://planipolis-iiep.unesco.org/upload/Angola/Angola-Leide-Leieducação.pdf. Acesso em 21.08.2014.

LERIA, Isabel (2006). Léxico, Aquisição e Ensino do Português Europeu Língua não Materna. Ed. Fundação Calouste Gulbenkian, Fundação para a Ciência e a Tecnologia. Lisboa.

LUBLINER, Shira; SMETANA, Linda (2005). Getting into Words. Vocabulary Instruction that Strengthens Comprehension. Baltimore. Paul H. Brooks Publishing. Co.

NAGY, William (1988). Teaching vocabulary to Improve Reading Comprehension. Newark. Delaware. International Reading Association. 
PINTO, Camila Ferreira (2012). Sinonímia, Polissemia, Homonímia em Manuais, Gramáticas e Dicionários Escolares para o desenvolvimento da Competência Lexical. (Tese - Doutorado) Faculdade de Ciências Sociais e Humanas Universidade Nova de Lisboa.

Programa Melhorado do Ensino Primário 6a classe Língua Portuguesa. Instituto Nacional de Investigação e Desenvolvimento da Educação/ Angola (INIDE) (s/d).

SIM-SIM, Inês (1998). Desenvolvimento da Linguagem. Universidade Aberta. Lisboa.

VILELA, Mário (1979). Estruturas Lexicais do Português. Livraria Almedina. Coimbra.

VILELA, Mário (1995). Ensino da Língua Portuguesa: Léxico, Dicionário, Gramática. Coimbra: Livraria Almedina.

XAVIER, Maria Francisca; MATEUS, Maria Helena (1992). Dicionário de Termos Linguísticos (Vol.II). Edições Cosmos. Lisboa.

João Muteteca Nauege é Doutor em Linguística Portuguesa, pela Universidade de Évora, Portugal. Mestre em Ciências da Linguagem, pela Faculdade de Ciências Sociais e Humanas, Universidade Nova de Lisboa. Investigador do Centro de Estudos em Letras (CEL) da Universidade de Évora, Portugal. Investigador do Centro de Estudos e Desenvolvimento Social da Universidade Lueji A'Nkonde, Angola (CEDES). E-mail: nauegejoaonauege@yahoo.com.br

Maria João Marçalo é Doutora em Linguística pela Universidade de Évora, pós-doutoramento em Linguística Aplicada pela Carnegie Mellon University, EUA. Professora com Agregação na Universidade de Évora, onde é Diretora do Programa de Doutoramento em Linguística. Investigadora do Centro de Estudos em Letras (CEL) da Universidade de Évora- UTAD, Portugal. Autora de Fundamentos para uma Gramática de Funções Aplicada ao Português. E-mail: mjm@uevora.pt 